in our knowledge requires new techniques, and biochemistry, histochemistry and electron microscopy offer new and exciting lines of attack on the more intimate pathology of the nervous system. They also widen the scope of what may be organic lesions. Much time and accuracy of correlation will be saved if the neuropathologist extends his methods into these new techniques. The first number has a truly international origin, and if this standard can be maintained this new journal will serve a very useful purpose.

\section{Industrial Sociology}

OF comparatively recent origin, industrial sociology is growing fast, and though its boundaries are somewhat indefinite it obtains a distinctive character by its specialized approach centring on the organization of work in society and the sociological analysis of industrial institutions and relationships. In a booklet entitled Industrial Sociology, recently added to the Unesco series on university teaching of social sciences, Mr. J. H. Smith suggests that the most fruitful application of the new subject will probably be found in those countries where industrialization is emerging or intensifying (Pp. 126. Paris: United Nations Educational, Scientific and Cultural Organization. 5.25 N.F.; 7s. $6 d$.; 1.50 dollars). There, problems of social change, and human adaptation to those changes, are of great urgency. Economic development, as, for example, in the Middle East or in Africa, depends on a concurrent social adaptation which may be more difficult to effect than economic or technological changes. The less-developed countries need to understand and to be prepared for the social changes which industrialization effects and there is a further need once industrialization is under way to understand the nature of the conflict newly created by an industrial re-deployment of labour. It is to be expected that industrial sociology will obtain greater recognition now that it has demonstrated its capacity to elucidate some of the critical problems arising in industry which are not adequately explained by other branches of the social sciences. Already in the United States, Britain, France and the Federal Republic of Germany, industrial sociology, though with differing emphasis, has found a place in university teaching of the social sciences and in technical education.

\section{Research in Public Health Administration}

Researce in public health administration is an ill-defined field, including few techniques that are not used in other types of research. In Research in Public Health Administration: Selected Recent Abstracts (Pp. 52. Baltimore, Md.: Research in Public Health Administration Project, School of Hygiene and Public Health, The Johns Hopkins University, 1962) the unit of study has been taken as the programme rather than the patient or the disease, and has been defined broadly to include all studies which give a firmer basis for administrative decisions. Studies of the distribution of disease or disability in the population are included in administrative research, for example, since they provide information needed to develop new programmes or improve existing ones. The booklet is planned for the beginner in research in public health administration, and not for the expert. It includes abstracts from recent papers which have clearly explained ideas, philosophies and techniques. It excludes examples of actual research projects in this field, since they are sufficiently numerous to justify a separate booklet. The abstracts have been edited by Prof. C. M. Wylie, who would welcome suggestions for additional papers to be covered in a future supplement to the volume.

\section{Active Dry Bakers' Yeast}

ALThough compressed wet yeast has been used in the preparation of baking bread since about 1860 , the production of active dry yeast started only recently. The advantages of active dry yeast over compressed yeast are long shelf-life (6-12 months) and ability to store well at ordinary temperatures. The commercial importance of active dry yeast has steadily increased since the Second World War when it began to be commercially used. Patented and published literature prior to that contains contradictory claims on procedures for making active dry yeast. Present methods of manufacture are kept confidential and scanty information is available in literature. Sufficient literature has accumulated on various scientific aspects of active dry yeast to justify a review of the literature, however, and this has been reported in the Journal of Scientific and Industrial Research by Y. S. Lewis, S. Neelakantan and D. S. Bhatia, of the Central Food Technological Research Institute, Mysore (20A; October 1961).

Fingerprints and Palmar Prints of Kalahari Bushmen

P. V. Tobras, assisted by J. Soussi and H. L. A. de Villiers, has made a study of the fingerprints of 327 Bushmen, drawn from the northern, central and southern groups (South African Journal of Science, 57, No. 12; December 1961). The Auen, like their fellow northern Bushmen, the Kung, depart from all other Bushmen studied in having few whorls and many arches, in which respect they closely resemble central African Pygmies. Central and southern Bushmen, on the other hand, have more whorls and fewer arches, their pattern approaching more closely that of Bantu-speaking Africans. This study provides the first evidence of differences in gene frequency between northern and central-southern Bushmen and of a possible genetic affinity between northern Bushmen and Eastern Pygmies.

\section{Education in Chemistry}

The Royal Institution of Chemistry has published a most useful Training Guide. The publication gives details of qualifications and courses, grants and scholarships, and of firms sponsoring works-based students undertaking sandwich courses in chemistry. There are also lists of universities and colleges offering full-time degree courses in chemistry, as well as particulars of technical colleges that offer fulltime, sandwich and part-time courses leading to Grad.R.I.C., Dip.Tech., B.Sc. external degree and Higher National Diploma qualifications in chemistry or applied chemistry. Copies of the Training Guide can be obtained from the Royal Institute of Chemistry, 30 Russell Square, London, W.C.1, price 2s. $6 d$.

\section{Open Days at the National Institute for Research in Dairying}

THE National Institute for Research in Dairying will celebrate its fiftieth anniversary by holding open days during June 28-29. The Institute is organizing tours of its farms, laboratories, engineering workshops and dairy, where experimental work will be on show, and there will be demonstrations of work relating to the physiology of the udder; the use of 